\title{
Impact of T3 thoracoscopic sympathectomy on pupillary function: a cause of partial Horner's syndrome?
}

\author{
Peter B. Licht • Christoph H. Schick • Georg Bischof - Alan A. E. P. Cameron • \\ Cliff P. Connery $\cdot$ J Ribas M. de Campos $\cdot$ Moshe Hashmonai
}

Received: 25 August 2012/Accepted: 18 October 2012/Published online: 7 February 2013

(C) Springer Science+Business Media New York 2013

We compliment Dr. Ramos et al. [1] for their important clinical observation. The observation of a partial Horner's syndrome raises the question of the nervous pathways responsible for each of the three components of this triad. The observation made by the authors supports the hypothesis that different pathways are responsible for each component. This hypothesis also has been suggested in a recent experimental study [2]. Dr. Ramos et al. reported that one of their patients developed ptosis. At what rib/ intercostal level was the T3 ganglion which ablation resulted in ptosis? How do the authors explain this event in a T3 sympathetic ablation? There is a substantial variability in the anatomy of the upper thoracic sympathetic chain. In a recent cadaveric study, Zhang et al. [3] found that the T3

This study was conducted on behalf of the International Society of Sympathetic Surgery (ISSS)

P. B. Licht

Odense University Hospital, Odense, Denmark

C. H. Schick

German Hyperhidrosiscentrum, Munich, Germany

G. Bischof

St Josef Krankenhaus, Vienna, Austria

\author{
A. A. E. P. Cameron \\ Ipswich, UK \\ C. P. Connery \\ St Luke's and Roosevelt Hospital, New York, NY, USA \\ JR. M. de Campos \\ Hospital Israelita Albert Einstein, Sao Paulo, Brazil \\ M. Hashmonai ( $\square)$ \\ Technion-Israel Institute of Technology, Haifa, Israel \\ e-mail: hashmonai@inter.net.il
}

ganglion was located in the third intercostal space only in $68 \%$ of examined hemi thoraces. It would be of interest to learn the exact surgical technique that they have used and, in particular, how did they identify the ganglion to be ablated.

Disclosures Peter B. Licht, Christoph H. Schick, Georg Bischof, Alan A.E.P. Cameron, Cliff P. Connery, J Ribas M. de Campos, and Moshe Hashmonai have no conflict of interest or financial ties to disclose.

\section{References}

1. Ramos R, Ureña A, Rivas F, Macia I, Rosado G, Pequeño S, Masuet C, Badia M, Miguel M, Delgado M-A, Escobar I, Moya J (2012) Impact of T3 thoracoscopic sympathectomy on pupillary function: a cause of partial Horner's syndrome? Surg Endosc 26:1146-1152

2. Kopelman D, Costa MG, Bejar J, Zareztky A, Hashmonai M (2012) Attempted reversible sympathetic ganglion block by an implantable neurostimulator. Interact Cardiovasc Thorac Surg 14:605-609

3. Zhang B, Li Z, Yang X, Li G, Wang Y, Cheng J, Tang X, Wang F (2009) Anatomical variations of the upper thoracic sympathetic chain. Clin Anat 22:595-600 